\title{
Fighting HIV/AIDS and Resilience Perspectives
}

\author{
Radha R Chada ${ }^{1, *}$, Venkat Pulla ${ }^{2}$, Bharath Bhushan Mamidi ${ }^{3}$, Azlinda Azman ${ }^{4}$ \\ ${ }^{1}$ Clinical Nutrition and Dietetics, Kasturba Gandhi Degree and PG College for Women, West Marredpally, Secunderabad, India \\ ${ }^{2}$ School of Social Sciences, University of the Sunshine Coast, Maroochydore, Australia \\ ${ }^{3}$ Centre for Action Research and People's Development, 8-3-228/267, Rahmath Nagar, Hyderabad, India \\ ${ }^{4}$ School of Social Sciences, Universiti Sains Malaysia \\ *Corresponding Author: chadaradha@yahoo.co.in
}

\begin{abstract}
People living with and affected by HIV still face stigma, discrimination and injustice in many countries despite the vision of reaching to zero new HIV infections, zero discrimination and zero AIDS-related deaths continues to be high on the global agenda. Restrictions on entry, stay and residence for people living with HIV still continue globally. People living with HIV/AIDS (PLWHA) are at risk of getting caught in a negative spiral involving poverty, stigma, discrimination, impaired immune function, increased risk of opportunistic infections, and increased nutritional needs. Owing to its tenacity, AIDS has exacerbated livelihood problems including poverty. This paper examines the wider set of social and economic drivers of HIV epidemics and the multiple downstream impacts of AIDS on societies and economies. It also analyses how households afflicted by AIDS adapt to the impact of the epidemic and further suggest ways to support households recover from impact.
\end{abstract}

Keywords PLWHA, AIDS, Stigma, Vulnerability, Downstream Impacts, Resiliency

\section{HIV/AIDS Prevalence}

Globally, about 34.0 million people were living with HIV at the end of 2011. An estimated $0.8 \%$ of adults aged $15-49$ years worldwide are living with HIV, with varying levels of the epidemic between countries and regions. There is dramatic progress in addressing the challenge of AIDS. The unprecedented progress "in lives saved and new infections averted will inspire hope around the world" in reducing the number of both adults and children newly infected with HIV, in lowering the numbers of people dying from AIDS-related causes (UNAIDS, 2012). There is significant progress across the countries with regard to their commitments to reach the targets of the 2011 United Nations Political Declaration on HIV and AIDS.

Countries across the world have highly varying percentage of people living with HIV (PLWHA). Sub-Saharan Africa is the world's most affected region by the pandemic, with nearly 1 in every 20 adults (4.9\%) living with HIV and accounting for $69 \%$ of the PLWHA worldwide. Although the regional prevalence of HIV infection is nearly 25 times higher in sub-Saharan Africa than in Asia, almost 5 million people are living with HIV in South, South-East and East Asia combined. After sub-Saharan Africa, the regions most heavily affected are the Caribbean and Eastern Europe and Central Asia, where $1.0 \%$ of adults were living with HIV in 2011. Worldwide, the number of people (adults and children) newly infected continues to fall, that is 2.5 million in 2011, which was $20 \%$ lower than in 2001 . The sharpest declines in the number of people acquiring HIV infection since 2001 have occurred in the Caribbean (42\%) and sub-Saharan Africa (25\%) (UNAIDS, 2012). There is a decreasing trend in the incidence rate of HIV infection among adults 15-49 years old, from 2001 to 2011, with $26.49 \%$ in Malaysia and $\geq$ $50 \%$ in India.

The number of people dying from AIDS-related causes began to decline in the mid 2000 s because of scaled-up antiretroviral therapy and the steady decline in HIV incidence since the peak in 1997. In 2011, 1.7 million people died from AIDS-related causes worldwide. This represents a $24 \%$ decline in AIDS-related mortality compared with 2005, when 2.3 million deaths occurred. The number of people dying from AIDS-related causes in sub-Saharan Africa declined by $32 \%$ from 2005 to 2011 , although the region still accounted for $70 \%$ of all the people dying from AIDS in 2011 (UNAIDS, 2012). Similarly, the Caribbean (48\%) and Oceania $(41 \%)$ experienced significant declines in AIDS-related deaths between 2005 and 2011. More modest declines occurred during the same period in Latin America $(10 \%)$, Asia (4\%) and Western and Central Europe and North America (1\%). Two other regions, however, experienced significant increases in mortality from AIDS Eastern Europe and Central Asia (21\%) and the Middle East and North Africa (17\%) (UNAIDS, 2012).

The HIV/AIDS pandemic has emerged as a developmental problem, having consequences going far beyond the health sector. Indeed, it has become a major crisis in many of the developing countries and in the absence of a cure or vaccine, 
the devastating impacts of the epidemic are far-reaching. The above figures may blur the true force of the epidemic, since HIV/AID impacts are not only felt by those affected, but indirectly affect a wider segment of the population with a significant number of orphans.

HIV continues to profoundly affect women and girls across all regions, with as high as $58 \%$ of the PLWHA being women and bearing the greatest burden of care. A recent review of available data from 50 countries, which estimated the global HIV prevalence among female sex workers at $12 \%$, found that female sex workers were 13.5 times more likely to be living with HIV than are other women (Baral et al., 2012). The lower socio economic and political status that women are assigned, unequal access to education and employment and fear or experience of violence compound to women's greater physiological vulnerability to HIV. Due to social and economic power imbalances between men and women, and the associated limitations in access to services, many women and girls have little capacity to negotiate sex, insist on condom use or otherwise take steps to protect themselves from HIV. Although the growing availability of HIV testing and prevention services in antenatal settings offers women an entry point to HIV services, the overall access to HIV services remains insufficient for pregnant women living with HIV and their male partners.

Although PLWHA in India constitute less than 1\% of the population, it ranks top second country in the world next only to South Africa in terms of number of PLWHAs in the world. India was estimated to be home of 5.13 million PLWHA in 2004 (Mehta et al., 2004). Owing to the large population base, a small rise of percentage points in HIV prevalence rates means increase of several million PLWHAs in India. They are predominantly men having sex with men (MSM), female sex workers (FSW) and recovering drug addicts in India (ADB, 2005). Around $8 \%$ to $32 \%$ of men who have sex with men are PLWHAs in Asian cities (Brahmam et al., 2008).

\section{Stigma, Vulnerability and Insecurities}

Substantial work across the world provided evidence that HIV/AIDS-related stigma is a barrier in HIV prevention work and in mitigating its impact (Mahajan et al., 2008). The National AIDS Control Program (NACO) of India recognized AIDS stigma as a significant barrier to HIV prevention efforts (NACO, 2006).There are several studies on stigma assessment (Mahajan et al., 2008) and on its role in hampering uptake of voluntary HIV counseling and testing (Day et al., 2003), adherence to antiretroviral treatment (Calin et al., 2007) and delaying general health seeking among people with HIV (Dunn et al., 2009).

Fear, ignorance and discrimination regarding HIV continue to exact profound human costs, including in the worst forms of abusive treatment and violence. Negative attitudes and beliefs within communities also aggravate internalized self-stigma, including guilt, shame and alienation felt by PLWHA. UNAIDS's report based on the People Living with HIV Stigma Index (PLWHSI) revealed that $52 \%$ of PLWHA in Zambia were verbally abused as a result of their HIV status and 1 in 5 PLWHA in Nigeria and Ethiopia reported feeling suicidal. Around $21 \%$ PLWHA reported being denied health services as a result of their HIV infection. Another study on discrimination at work place in nine countries revealed that PLWHAs suffering discriminatory attitude among employers and co-workers constituted $8 \%$ in Estonia to $54 \%$ in Malaysia (ILO \& GNPLHWA, 2012).

Conventional perceptions about the impacts of HIV/AIDS predicted were intensification of hunger, dissolution of thousands of households and many children orphaned. Owing to its tenacity, AIDS has exacerbated livelihood problems including poverty, but it has not entirely weighed down the social fabric of society. Despite a widespread knowledge on HIV transmission and efforts to address and reduce stigma, in many parts of the world, PLWHA are still seen as shameful and irresponsible. Regardless of how people become infected with HIV, the assumption is that the infection is the result of morally questionable behavior because it is believed that PLWHA have brought disease upon themselves by having sex with many partners and are therefore immoral and sinners (Nombo, 2007; Azlinda Azman, 2010). Owing to the strong perception of HIV/AIDS linked with morality the affected people are subject to stigmatization, and ultimately excluded from the family and the wider community. Another disadvantage of stigmatization is the pressure on PLWHA to hide the problem and avoid seeking counseling and testing for fear of being stigmatized.

Men and women experience HIV/AIDS impacts differently. Women experience more stigma and discrimination related to HIV/AIDS than men, because of the gendered societal perceptions on promiscuity and sexuality. It is accepted for men to have multiple sexual relationships but not for women. Social norms based on patriarchy accepts men to have multiple partners but women to be innocent, married and live with one man only, and any different behaviour subjects women to stigmatization. Because of their subordinate status in society, many women are stigmatized as the vector of HIV transmission. Affected persons are regarded unworthy by their family and in their community, which increases the chances of being stigmatized. HIV/AIDS impacts and susceptibility are gendered (Müller, 2005) and women and orphans are observed to be facing greater food shortage (Bharat et al., 2001; UNAIDS, 1999; Gillian, 1996; ICRW, 2003). Women affected by HIV/AIDS suffer more due to loss of assets caused by disinheritance, and exclusion from kinship and other social networks. Women's role in care giving and food procuring and preparing have not only become more critical in the context of HIV/AIDS but also more difficult for the women because of HIV/AIDS epidemic gender inequalities in access to resources (Niehof, 2003).

Stigmatization as a means for production and reproduction 
of structural inequalities intensifies impact of stigma for some individuals and groups (Bharat, 2011; Parker \& Aggleton, 2003). Studies revealed that "HIV/AIDS-related stigma builds upon and fuels existing prejudices and inequities of class, gender and sexualities" (Bharat, 2011; Parker \& Aggleton, 2003; Maluwa et al., 2002). The stigma surrounding HIV/AIDS leads to alienation from one's means of survival and social safety nets. The stigma affects the individual's and the household's participation in work, as well as in "informal social networks and community groups" (Nombo, 2007) and thereby deprives them of the support structure.It plays a major role in worsening HIV infection, obstructing care and support to affected members in the households and in the community.

Both stigma and discrimination may occur at family and community or at institutional levels such as workplace, school, or health care settings. In addition, both may take overt (visible) or covert (hidden) forms. Hiding HIV-status forms a barrier for prevention and treatment. People are reluctant to go for testing because the perceived advantages of testing are considered less significant compared to likely stigmatization when tested positive. Those who are known to be HIV-positive are an object of discussion in the community and are pointed at as being responsible for some deaths. Mariame Maiga's study in 2010, in rural Côte d'lvoire revealed that PLWHA are not able to observe the counseling and treatment protocols because of the pressure to keep their affliction secretive.

\section{Coping Mechanisms / Resilience}

AIDS is seen as a "long wave event" taking years for the epidemic to spread through the society and generations for the full impact to be felt. Vulnerability in the context of AIDS has three phases: Upstream (relating to risk of an individual becoming exposed to, and infected with HIV), Midstream (individual risk of developing opportunistic infections after HIV infection), and Downstream (risk of serious impacts in households or communities living with HIV).

Epidemic of HIV/AIDS has brought new challenges, pressures and functions to be played by the family, community and government. HIV/AIDS impact has varying implications to the community, social network and government agencies owing to the magnitude or percentage of the PLWHA households to the total population. Long term approach towards achieving treatment targets requires a nation to facilitate both formal and informal institutions to collectively address the challenge of HIV/AIDS. It is observed that a nation "has to instill a fully caring society and a and caring culture, as well as a social system in which the society will come before self with the welfare of the people to revolve around a resilient family system" (Azlinda Azman, 2010).

HIV/AIDS is an important health related shock that lead households into poverty and destitution.Households face severe shocks with long and expensive illness such as HIV/AIDS that threaten livelihood capabilities and also survival. Often these shocks push the households into chronic or long-term poverty. HIV/AIDS is also responsible for intergenerational transmission of poverty because of the loss of incomes from adult members and younger ones are not equipped with skills and capacity to find their own way out of poverty (Slater \& Wiggins, 2005). Serious concerns of food security are observed in the context of HIV/AIDS with affected people losing ability to work to earn their bread. Post-infection longevity of the PLWHA depends on awareness about and access to anti retroviral therapy (ART), which is expensive and unaffordable for the poor. It is a severe concern for the poor in India because access to public health is grossly inadequate forcing them to depend on private medical practitioners (Gupta \& Datta, 2003). HIV/AIDS induced poverty is of two types viz., 'service poverty' due to barriers in accessing services such as health and education and 'resource poverty' because of inability to access resources due to poverty. In some communities with large number of PLWHA, there is a 'New Variant Famine' growing, not by drought or conflict, but by the effects of HIV/AIDS that aggravates vulnerability of households to shocks and risk (de Waal, 2003; FANTA, 2001; WHO, 2003).

HIV/AIDS affects people in different spheres of their lives. Consequences of being affected by HIV is manifested in many ways such as a lower life expectancy, an increased economic dependency ratio, reduced productivity, increasing poverty and a growing number of orphans.Studies in Tanzania where HIV/AIDS is a serious threat revealed that "affected households are poorer than non-affected ones, and have responded to their adversity by adopting food-search behaviours that removes both adult and child labour from working on their own farms, thus leaving the affected households perpetually food insecure". Households fostering orphans have similar problems (Tumushabe, 2005; Nombo, 2007).

The HIV/AIDS epidemic has adverse impact on food security and rural livelihoods. HIV/AIDS induced morbidity and mortality erodes household preparedness for "future shocks" and ability for livelihoods owing to loss of productive labour, income and food reserves (Nombo, 2007). Several studies have presented evidence on adverse impact of HIV/AIDS on livelihoods and social capital. Adult morbidity and mortality due to AIDS caused loss of incomes and livelihoods and led to food insecurities as the savings and assets are consumed to meet health care and food requirements of the households. Impoverishment and food insecurities due to AIDS induced morbidity and mortality among adults makes some households totally dependent on support of the community (Barnett \& Rugalema, 2001). Problems of poverty and debt are so severe that in some households meeting funeral costs are also issues of concern (Nombo, 2007). Rugalema's study (1999) reveals that 
prolonged adult morbidity and mortality due to AIDS have adverse effects on households primarily due to their effects on labour availability and depletion of other household resources. Rugalema confirms that illness and death affect time allocation, change household composition, put pressure on available labour, divert household cash, and lead to disposal of a household's productive assets and render survivors vulnerable. Increasing number of households and individuals affected by HIV/AIDS are compelled to seek support from the extended family, neighbours, community institutions and the government (Robb \& Caroline, 1998; Rugalema, 1999; Lundberg et al., 2000; Mutangadura et al., 1999).

Varied agencies and institutions, both formal and informal, offer insights into coping strategies in communities under severe pressure with regard to the challenges posed by HIV/AIDS.Social networks between households of different kinds provide a sort of safety net for households that face various problems, which may prevent them from falling into poverty. Therefore social capital is an asset that can be used to diminish individuals and households' vulnerability to poverty and a means to sustain livelihoods. Although all households can be affected by stress and shocks, not all households are equally resilient. The extent to which households can make claims on social networks depends on their ability to build up their social capital (Nombo, 2007).

It is also found that because of AIDS, the normal household cycle is disrupted, resulting in a variety of household types in terms of composition and headship, including households headed by orphans, the elderly and widows (Rugalema, 1999; du Preez, 2011). The household's asset base, gender and age of the survivors determine the household's ability to mitigate the effects of HIV/AIDS.

HIV/AIDS induced impacts are indeed a process rather than a final outcome. Individuals and households are not passive; they actively explore ways to deal with the hardship brought about by AIDS. The household is considered an arena of potential conflict because of these variations, but at the same time it provides the context of cooperation based on trust and shared values, which form the basis of joint household strategies. Cooperation is very important when it comes to coping with the consequences of HIV/AIDS. Rugalema (1999) and Preez (2011) showed how households relocate and transform their resources to cope with the losses induced by AIDS. The household's ability to solicit resources by virtue of its membership in various social networks of relatives, neighbours and friends is important in coping with social emergencies. Thus households are not isolated units but maintain linkages with the wider society. Relations beyond the household are an important source of social support for most households.

The livelihood framework applied in the context of households affected by HIV/AIDS examine how the five groups of assets being the natural capital, human capital, physical capital, social capital, and financial capital are combined in different ways to generate livelihood outcomes (Ellis, 2000). The vulnerability context of the affected groups includes impact of seasonality, shocks and trends on people's assets and options available to them. Threats that affect vulnerability can include illness and death. Thus the most direct impact of HIV/AIDS on households refers to the loss of human capital (skills and knowledge) that is essential for pursuing livelihood activities. HIV/AIDS severely affects human capital due to morbidity and mortality of household members.

The household represents 'the arena of everyday life' for the majority of people (Clay \& Schwartzweller, 1991). The care giving to the young, sick, disabled, and old members is part of the function of the household. Care is especially important to the sick and orphaned in times of HIV/AIDS because of the prolonged nature of illness and ensuing dependence. Competencies and resources are needed to provide adequate care (Niehof, 2003). In highly HIV/AIDS-affected countries, support from outside the households is decreasing while care needs are increasing due to effects of AIDS and economic hardships. As a consequence of HIV/AIDS impacts, affected households lack the necessary resources to provide care and other basic necessities. Food provision to household members is an important aspect of care.

The impact of HIV/AIDS on household labour availability is not only direct but also indirect, because productive time is diverted to taking care of the sick. HIV/AIDS has a greater impact on poor than better-off households as it forces the former to draw on their already limited resources in order to cushion the shock. This threatens their ability to respond to future insecurity. Although HIV/AIDS impacts resemble other shocks, they differ in the way they affect the labour potential of adults in their prime years in addition to the impacts being gendered. Food security is defined as access by all people at all time to enough food for an active and healthy life (World Bank, 1986; FAO, 1997). Food security is a basic need in human life and an important element of sustainable livelihood (Niehof \& Price, 2001).

According to the sustainable livelihood approach, food security is not just an issue of productivity but is about how people, especially poor, gain access to production and can exchange capabilities in order to get food (Swift \& Hamilton, 2001). The definition has been broadened to include elements of access, vulnerability and sustainability. However, since the household's food security is a woman's major concern, due to their gender role, women are always concerned about its safeguarding and will initiate coping strategies when their household's food security is threatened (Niehof, 1999, 2003, 2010). Wisner et al., (2004) defines vulnerability as the characteristics of a person or group and their situation that influence their capacity to anticipate, cope with, resist and recover from the impact of natural hazards. Vulnerability also measures the resilience against risks.

Adaptive capacity, defined as those characteristics of an individual, household, or population group that enable those concerned to alter or structurally reorganize their activities to diminish present threats to survival while enhancing its ability to address new risks. In most cases, the coping 
strategies are associated with success rather than with failure of livelihood systems. Coping is defined as the ability to deal successfully with the stress, success implying that individuals or households are able to escape from insecurity and keep their livelihoods sustainable. Not all coping responses that individuals or households employ are successful. In fact sometimes, coping could be an indication that things are getting worse. In the case of HIV/AIDS impacts, dissolution of the household is an indicator of failure to cope. Coping strategies and responses vary according to vulnerability status and are influenced by asset ownership. In developing countries, coping strategies and responses of the poor are often strained because of HIV/AIDS and a number of other problems. Families live with HIV, not just individuals (Rotheram - Borus et al., 2005). If an individual in the household is affected, the impacts of the epidemic are shared through kinship relations, neighborhood relations and other social relations within and between households. As the epidemic unfolds, household and family structures are affected and these changes are extended to the community, exerting an increasing strain. Not all individuals and households are supported, may be because of their weak kinship ties or as a consequence of the stigma represented by AIDS. A recurrent coping mechanism observed in India was to pull female children out of school to care and maintain the family (Mukhopadhyay et al., 2001).

Studies show that the quantity, quality and persistence of social interactions among neighbours, friends and members of groups and associations, generate social capital and the ability to work together for a common end, which is especially important for the poor (Grootaert et al., 1999; Moser, 1998). Wider social relationships and the degree of social cohesion in the community may affect individual's health and feeling of safety (Wilkinson, 2002). Social capital is regarded as particularly important as a last resort resource for the poor and vulnerable. It can provide a buffer that helps them cope with shocks, such as death in the family, functioning as an informal safety net to ensure survival during periods of intense insecurity. Social capital provided by family and close friends provides assistance and care and also creates a sense of well-being. In HIV/AIDS situation, social capital has been said to facilitate households to respond to its impacts. When it comes to support and survival, personal relationships and social networks are crucial. Portes (1998) observes, whereas economic capital is in people's bank accounts and human capital is inside their heads, social capital is inherent in the structure of their relationships.

The combination of the conditions due to HIV/AIDS, like access to land as the lack of (male) labour within the family due to illness, and the lack of time to farm, due to the time that is allocated to caring for the sick, along with the related financial impacts severely add to the internal vulnerability, as it impacts on their food and livelihood security. Households may rely on their social capital to cope with the internal vulnerability. It is revealed that AIDS-related economic hardship impacts on social capital, as vulnerable households face constraints to maintain their participation in social networks, because they lack the resources and time to invest in and sustain their social capital (Nombo, 2007; Nombo \& Niehof, 2008).

Walker et al.,(2004), indicate resilience as 'the capacity of a system to absorb disturbance and reorganize while undergoing change so as to still retain essentially the same function, structure, identity, and feedbacks'. In the literature, resilience captures a 'bounce-back-ability' (Davis, 1993). In a context of ill health and other adversity, resilience refers to people's ability to challenge the devastating impacts of AIDS, i.e. improve their health and regain a certain well-being, in areas such as their income, education, and food security (Loevinson \& Gillespie, 2003; Niehof, 2008). In Matinga's (2008) view, resilience as the ability to bounce back differs from the ability to endure hardship, which she refers to as 'hardiness' or 'toughness'. It is important to understand the subjective and qualitative dimensions of resilience, particularly how it is socially, culturally and institutionally embedded, and how resilience is gendered.

\section{Conclusions}

Overall, dealing with HIV/AIDS is very challenging for many individuals and families. The impact of HIV/AIDS is enormous as it involves not only the health conditions, but also the socioeconomic aspects which all affect the livelihood of the infected individuals. The sufferings of PLWHA, particularly among women and children are much more complex as it involves all kind of stigma and discriminations from the community or society. There is a strong need for social support for those living with HIV/AIDS, not only from the family members, but other services provided by relevant stakeholders and society. Continuous social support able to enhance individuals and families' resiliency is dealing with the current sickness. However, the development and strengthening of resiliencies among PLWHA is very much dependent on the available resources as well as strong social interaction and cohesion that further leads to stronger social capital and social support.In fact, the ability to cope and becoming more resilience able to reduce the vulnerable PLWHA from continuously entrapped in many form of problems that may have an adverse impact on their livelihood.

\section{REFERENCES}

ADB (2005). Development, Poverty and HIV/AIDS: ADB's Strategic Response To A Growing Epidemic.

Anderson, M.D. and Cook, J.T. (1999). Community food security: Practice in need of theory. Agriculture and Human Values, 16: 
$141-150$

Azlinda Azman (2010). An Overview: Nurturing Care in HIV/AIDS Response, in Azlinda, A et al., (eds) Malaysia HIV/AIDS- Prevention, Treatment and Care: The Way Forward, AIDS Action \& Research Group, Universiti Sains Malaysia, Penang, pp. 1-8.

Baral S, Beyrer C, Muessig K, Poteat T, Wirtz AL, Decker MR, Sherman SG, Kerrigan D (2012). Burden of HIV among female sex workers in low-income and middle-income countries: a systematic review and meta-analysis. Lancet Infectious Diseases, 2012, 12:538-549

Barnett, T. and Rugalema, G. (2001). Health and nutrition emerging and reemerging issue in developing countries. Washington DC: IFPRI.

Barnett, T. and Blaikie, P. (1992). AIDS in Africa: Its Present and Future Impact. London: Bellhaven Press.

Barnett, T., Tumushabe, J., Bantebya, G., Ssebuliba, R., Ngasongwa, J., Kapinga, D., Ndelike, M., Drinkwater, M., Mitti, G. and Haslwimmer, M. (1995). 'The Social and Economic Impact of HIV/AIDS on Farming Systems and Livelihoods in Rural Africa: Some Experience and Lessons from Uganda, Tanzania and Zambia'. Journal of International Development, 7 (1), 163-76.

Barnett, T and Whiteside, A. (2002). 'Poverty and HIV/AIDS: Impact, Coping and Mitigation Policy', in Giovanni Andrea Cornia (ed.), AIDS, Public Policy and Child Well-Being. (available online

http://www.unicef-icdc.org/research/ESP/aids/chapter11.pdf).

Bharat, S., Aggleton, P. and Tyrer, P. (2001). India: HIV and AIDS-related discrimination, stigmatization and denial, in UNAIDS Key material-Best practice collection. Geneva: UNAIDS. www.unaids.org/publications/documents/

Bharat, S. (2011). A systematic review of HIV/AIDS-related stigma and discrimination in India: Current understanding and future needs. Journal of Social Aspects of HIV/AIDS, vol. 8 No. 3 September 2011. Downloaded by [14.99.112.60] at 22:46 12 August 2013. http://www.tandfonline.com/doi/pdf/10.1080/17290 376.2011.9724996.

Brahmam GN, Kodavalla V, Rajkumar H, Rachakulla HK, Kallam S, Myakala SP, Paranjape RS, Gupte MD, Ramakrishnan L, Kohli A, Ramesh BM; IBBA Study Team. (2008). Sexual practices, HIV and sexually transmitted infections among self-identified men who have sex with men in four high HIV prevalence states in India. AIDS, 22(Suppl. 5):S45-S57.

Calin, T., Green, J., Hetherton,J., and Brook, G. (2007). Disclosure of HIV among black African men and women attending a London HIV clinic. AIDS Care, 19, 385-391.

Clay, C.D. and Schwartzweller, H.K. (1991). Introduction: Researching household strategies. Research in Rural Sociology and Development, 5: 1-11.

Davies, S. (1993). Are coping strategies a cop out? IDS Bulletin, 24:60-72.

Day, J.H., Miyamura, K., Grant A.D., Leeuw, A., Munsamy, J., Baggaley, R., and Churchyard, G.J. (2003). Attitudes to HIV voluntary counseling and testing among mineworkers in South Africa: Will availability of antiretroviral therapy encourage testing? AIDS Care, 15, 665-672.

de Waal, A. (2003). "New Variant Famine": Hypothesis, Evidence and Implications'. Humanitarian Exchange, 23, 20-22.

du Preez, C.J. (2011). Living and Care Arrangements of Non-urban Households in KwaZulu-Natal, South Africa, in the Context of HIV and AIDS. Thesis Submitted in fulfilment of the requirements for the degree of doctor at Wageningen University, Wageningen, the Netherlands.

Dunn et al. (2009). Delaying care, avoiding stigma: residents attitudes toward obtaining personal health care. Academic Medicine, 84(2), 242-250.

Ellis, F. (2000), Rural livelihoods and Diversity in Developing Countries. Oxford: Oxford University Press.).

Food and Nutrition Technical Assistance (2001). HIV/AIDS: A Guide for Nutrition, Care and Support. Washington, DC: FANTA.

Gillespie, S. and Loevinsohn, M. (2003). 'HIV/AIDS, Food Security and Rural Livelihoods: Understanding and Responding'. RENEWAL Working Paper No. 3. Washington, DC: International Food Policy Research Institute.

Global Network of People Living with HIV (2012). Sigma and discrimination at work: findings from the People Living with HIV Stigma Index. Amsterdam,

http://www.gnpplus.net/images/stories/Rights_and_stigma/SI_Wo rkBriefing_Online.pdf.

Grootaert, C., Oh, G.T., and Swamy, A. (1999). The local level institutions study: Social capital and development outcomes in Burkina Faso. Local Level Institutions Working Paper No.7. Washington DC: World Bank.

Gupta, I., and Datta, A. (2003). Inequities in Health and Health Care in India: Can the Poor Hope for a Respite? Institute of Economic Growth, Delhi, December. (available online ieg.nic.in/dis_ind_80.pdf).

Lundberg, M., Over, M., and Mujinja, P. (2000). Sources of financial assistance for households suffering an adult death in Kagera, Tanzania. The South African Journal of Economics 68 (5): 139.Policy Research Working Paper 2508.

http://www-wds.worldbank.org/servlet/WDSContentServer/WDS P/IB/2001/01/26/000094946_0101170531277/Rendered/PDF/mult i page.pdf

Mahajan, A.P, et al. (2008). Stigma in the HIV/AIDS epidemic: A review of the literature and recommendations for the way forward. AIDS, 22 (supplement 2), S67-S79.

Maluwa, M., Aggleton, P., and Parker, R. (2002). HIV- and AIDSrelated stigma, discrimination and human rights. Health and Human Rights, 6, 1-18.

Mariame Maiga (2010). Gender, AIDS, and Food Security: culture, and vulnerability in rural Côte d' lvoire. Awlae series. Wageningen Academic Publishers: Wageningen, the Netherlands

Matinga, M.N. (2008). The making of hardiness in women's experience of health impacts of wood collection and use in Cuntwini, rural South Africa. Medische Antropologie, 20(2):279-296.

Mehta, Aasha, K., and Bhide, S. (2003). 'Issues in Chronic Poverty: Panel Data based Analysis', in Mehta, Aasha Kapur et. al., Chronic Poverty in India. Delhi: Indian Institute of Public Administration.

Mehta, Aasha, K., and Shepherd, A. (2004). 'Chronic Poverty in 
India: Overview of Key Emerging Issues', Working Paper 24, CRPC-IIPA, New Delhi.

Molyneux, M. (2002). Gender and the silence of social capital: lessons from Latin America. Development and change 33(2): $167-188$

https://www.uio.no/studier/emner/sv/sai/SOSANT2530/v13/molyn eux_gender_and_the_silences.pdf

Moser, C. (1998). Gender planning in the Third World: meeting practical and strategic gender needs. World Development 30 (3): 435- 464.

Mukhopadhyay, Swapna et. al. (2001). Living Under a Shadow: Gender and HIV/AIDS in Delhi. Delhi: ISST.

Müller, T. (2005). HIV/AIDS, gender and rural livelihoods in sub-Saharan Africa. An overview and annotated bibliography. Wageningen: Wageningen Academic Publishers.

Mutangadura, G., Mukurazita, D., and Jackson, H. (1999). A review of household and community responses to the HIV/AIDS in rural areas of sub-Sahara Africa. UNAIDS Best Practice Paper. Geneva: UNAIDS.

http://www.unaids.org/en/media/unaids/contentassets/dataimport/p ublications/irc-pub04/una99-39_en.pdf

NACO (2006). National AIDS Control Program- Phase III (2006-11: Strategy and implementation plan. Ministry of Health \& Family Welfare, Government of India. pg. 6.

Niehof, A. (1999). The gendered nature of household food security. in: Niehof, A., and Tepstra, P. (eds.), Household in an interdisciplinary perspective. Liber Amicorum for Antine Hardon-Baars, Household and Consumer Studies Publication Series 2, Wageningen Agricultural University: Wageningen, the Netherlands, pp. 105-119.

Niehof, A. (2003). Gendered dynamics of food security at the household level. In: U. Karim (Ed.) No security without food security-No food security without gender equality. Association of World Council of Churches Related Development Organisations in Europe (APRODEV) GOOD Conference Report, Brussels: APRODEV, pp. 60- 68.

http://webcache.googleusercontent.com/search?q=cache:http://apr odev.eu/files/Gender/APRODEV_NoSecurityWithoutFoodSecurit y_2002.pdf

Niehof, A. (2008). Introduction: dimensions of resilience in a context of health-related adversity. Medische Antropologie, 20(2): 217-226.

Niehof, A. (2010). Food, diversity, vulnerability and social change: research findings from insular Southeast Asia. Mansholt Publication Series No. 9. Wageningen Academic Publishers: Wageningen, the Netherlands.

Niehof, A. and Price, L. (2001). Rural livelihood systems: A conceptual framework. Wageningen- UPWARD Series on Rural Livelihoods No. 1. Wageningen: WU-UPWARD.

Nombo, C. (2007). When AIDS meets poverty: Implications for social capital in a village in Tanzania. Awlae series 5. Wageningen Academic Publishers: Wageningen, the Netherlands.

Nombo, C. and Niehof, A. (2008). Resilience of HIV/AIDS-affected households in a village in Tanzania: Does social capital help? Medische Antropologie, 20(2): 241-258.)

Parker, R., and Aggleton, P. (2003). HIV and AIDS-related stigma and discrimination: A conceptual framework and implications for action. Social Science \& Medicine, 57, 13-24.

Portes, A. (1998). Social Capital: its origins and applications in modern sociology. Annual Review of Sociology 22: 1-24.

Robb, C. M. (1998). Social aspects of the East Asian financial crisis: perceptions of poor communities. Paper presented at the East Asia Crisis workshop at the Institute of Development Studies. http://www.ids.ac.uk/files/DP367.pdf.,

http://www.ids.ac.uk/ids/research/robb.pdf Accessed on 9/08/13: 1050 .

Rotheram-Borus, M.J., Flannery, D., and Lester, P. (2005). Families living with HIV. AIDS Care 17 (8): 978-987.

Rugalema, G. (1999). Adult mortality as entitlement failure: AIDS and the crisis of rural livelihoods in a Tanzanian village.

http://www.macalester.edu/academics/geography/agr/journals/199 8_20_2_2.pdf

Slater, R. and Wiggins, S. (2005). 'Responding to HIV/AIDS in Agriculture and Related Activities'. Natural Resource Perspectives No. 98. London: Overseas Development Institute.

Swift, J. and Hamilton, K. (2001). Household food security and livelihood security. In: S. Devereux \& S. Maxwell (Eds.) Food security in Sub-Saharan Africa. London: ITDG Publishing, pp. 67-92.

Tumushabe, J. (2005). HIV/AIDS and the changing vulnerability to Crisis in Tanzania: Implications for food security and poverty eradication. A paper presented in the International Conference on HIV/AIDS, Food and Nutrition Security, April 14-16, 2005 Durban, South Africa.

UNAIDS, 2012. Together we will end Aids. Joint United Nations Programme on HIV/AIDS, "UNAIDS / JC2296E".

(http://www.unaids.org/en/media/unaids/contentassets/documents/ epidemiology/2012/jc2296_unaids_togetherreport_2012_en.pdf

Walker, B., Holling, C.S., Carpenter, S.R., and Kinzig, A. (2004). Resilience, adaptability and transformability in social-ecological systems. Ecology and Society 9(2): 5.

Available at: http://www.ecologyandsociety.org/vol19/iss2/art5/

Wilkinson, R.G. (2002). Commentary: liberty, fraternity, equality. International Journal of Epidemiology 31: 538-543.

Wisner, B., Blaikie, P., Cannon, T., and Davis, I. (2004). At Risk: Natural Hazards, People's Vulnerability and Disaster. London: Routledge (2nd Edition)

World Health Organization (2003). 'Nutrition Requirements for People Living with HIV/AIDS'. Report of a technical consultation. Geneva, 13-15 May. 